\title{
Single-organ polyarteritis nodosa
}

INSERM

\section{Source}

INSERM. (1999). Orphanet: an online rare disease and orphan drug data base. Singleorgan polyarteritis nodosa. ORPHA:439755

Single-org an polyarteritis nodosa (PAN) is a rare, often mild form of PAN characterized by limited disease without generalized manifestations, most often affecting the skin (cutaneous PAN; see this term), the brain, eyes, pancreas, testicles, ureter, breasts, or ovaries. Affected patients are often younger than those with systemic PAN (see this term) and relapses appear to be more common. 